\title{
BIOCHEMICAL MUTANTS OF BACTERIAL VIRUSES ${ }^{1}$
}

\author{
M. DELBRUCK \\ California Institute of Technology, Pasadena 4, California \\ Received for publication January 30, 1948
}

Two years ago T. F. Anderson (1945a) reported the remarkable discovery that certain strains of bacterial virus (T4 and T6) require organic substances as cofactors for the process of adsorption of the virus on the bacterial host strain B of Escherichia coli. Tryptophan in its I form is the substance most active in promoting adsorption of phage to bacterium, about $1 \mu \mathrm{g}$ per $\mathrm{ml}$ being sufficient for maximum effect. Other substances, like phenylalanine and tyrosine, and several tryptophan analogues are also active, though only at higher concentrations (T. F. Anderson, 1945b, 1946). Anderson (1948) has shown that the function of the cofactor is to "activate" the phage particle reversibly, and that phage particles activated in this way will become deactivated in the absence of extraneous cofactor with a half-life of the order of one-half minute.

We wish to report some observations on the mutability of phage T4 with respect to cofactor requirements, and on certain features throwing additional light on the mechanism of cofactor action.

We were led to undertake these studies by the desire to have available a greater variety of phage mutants for genetic studies in bacterial viruses. Luria (1945) and Hershey $(1946 a, b)$ have previously described host range and plaque morphology mutants of phages, and we (Delbrück and Bailey, 1946) have reported on a peculiar transfer of genetic markers from one phage to another during mixed infections of bacteria with two different phages. Luria (1947) has recently analyzed a phenomenon of "reactivation" of irradiated phages in mixed infections and has interpreted his findings on the assumption of a similar transfer of genetic material from one phage particle to another. For further analysis of the mechanisms involved the availability of a greater variety of mutant types is clearly desirable. Anderson's discovery offered the hope of finding mutations with respect to biochemical requirements of the phage.

We have found three clearly distinct mutant types of T4, as follows: (1) a type requiring no cofactor; (2) a type requiring tryptophan or similar substances; and (3) a type requiring tryptophan or similar substances and in addition requiring $\mathrm{Ca}^{++}$ions. There appears to be some correlation between cofactor requirement and plaque morphology. Each mutant that does not require a cofactor gives small plaques with a sharper margin than those of the wild type.

We have also found that indole (and to a lesser extent skatole) inhibits the adsorption of the mutants requiring tryptophan for adsorption.

1 The experimental work described in this paper was performed in the Department of Biology of Vanderbilt University, Nashville, Tennessee, and it was supported by grants from the Rockefeller Foundation and from the John and Mary R. Markle Foundation. 


\section{MATERIALS AND METHODS}

\section{Starting Material and Isolation of Mutants}

Anderson noticed the cofactor requirement of phage strains T4 and T6 when plating these stocks on petri plates containing a synthetic medium agar. ${ }^{2}$ On these plates the plaque counts of Anderson's T4 and T6 stocks were much lower than on parallel broth plates. In going through our stocks of T4 we found that stocks made with synthetic media gave very similar plaque counts on synthetic medium plates and on broth plates. Presumably during the growth of these stocks a selection of mutants of $\mathrm{T} 4$ not requiring cofactors had taken place. However, an old broth stock showed the Anderson phenomenon, a much lower plaque count on synthetic medium plates than on broth plates. Moreover the platings on broth showed three distinguishable types of plaque, viz.: (1) "f," wild type, plaques with fuzzy edge; (2) "s," plaques with very sharp edge (Hershey, $1946 a, b)$; and (3) "r," plaques with clear halo (Hershey, 1946a,b). Several plaques of each type were picked and their contents plated out in parallel on $\mathbf{F}$ and on broth plates. Each of the three types bred true on subculture (except for small proportions of mutants). The s plaques gave the same plaque counts on $F$ and on broth, whereas the fuzzy and the $r$ types gave very low or zero plaque counts on $\mathrm{F}$ plates. From broth plates of these stocks $\mathrm{s}, \mathrm{f}$, and $\mathrm{r}$ plaques were picked again and broth stocks were made. When these stocks were tested for deficiencies again, the s stock was found nondeficient, and the wild-type stock and the $r$ were found deficient.

\section{Notation}

We designate each stock obtained from a single plaque and grown in liquid medium with a serial number. Thus, the three stocks just mentioned will be called: T4,1 (s type, nondeficient); T4,2 (f type, deficient); and T4,3 ( $\mathrm{r}$ type, deficient). Such stocks need not be pure stocks. They may contain an admixture of mutants that arose during the growth of the plaque and during the subsequent growth of the stock in liquid medium. In general this admixture of mutants will amount to at most a few per cent. Thus, T4,1 contains about 10 per cent wild-type plaques; T4,2 contains about 1 per cent $r$ plaques; and $\mathrm{T} 4,3$ contains less than 0.1 per cent of mutants giving plaques that are not of the $\mathbf{r}$ type. In some cases, when a mutation occurred early during the growth of a plaque from which a stock is isolated, the stock may be not even approximately pure. The stock $\mathrm{T} 4,5$, for instance, isolated from a single plaque on a broth plate and grown in broth, contained 25 per cent particles adsorbable with tryptophan only, and 75 per cent particles requiring other cofactors besides tryptophan.

2 Composition of our synthetic medium (F medium), which is similar to that of T. F. Anderson (1945a); Na-lactate $10 \mathrm{~g}, \mathrm{NH}_{4} \mathrm{Cl} 1 \mathrm{~g}, \mathrm{KH}_{2} \mathrm{PO}, 1.5 \mathrm{~g}, \mathrm{Na}_{2} \mathrm{HPO}_{4} 3.5 \mathrm{~g}, \mathrm{MgSO} 40.1 \mathrm{~g}$, $\mathrm{H}_{2} \mathrm{O}$ (redistilled) $1,000 \mathrm{ml}$. 


\section{Measurement of Adsorption}

The degree to which adsorption takes place in a given mixture of bacteria and phage can be determined in several ways:

(1) The adsorbed phage can be sedimented with the bacteria to which it is adsorbed and the free phage determined by a plaque count of the supernatant. The adsorbed fraction is then determined as the difference between the total phage and the free phage. This method is rather inaccurate when adsorption is slight and in such a case does not tell more than that the fraction adsorbed was less than, say, 10 per cent of the total.

(2) T. F. Anderson (1945a) has found that in cofactor-requiring stocks the adsorbed fraction can be determined directly by plating on the basal medium. On such plates free phage particles will not form plaques, whereas phage particles that were adsorbed to bacteria at the time of plating will form plaques even though no cofactor is added to the plate. Presumably the infected bacteria upon lysis yield a proportion of phage particles that are temporarily adsorbable without the need of extraneous cofactors. The bacteria may contain cofactor substances in sufficiently high concentration to activate the phage particles before their release, and a few particles may infect other bacteria on the plate before becoming deactivated. This is a hypothetical mechanism; but, whatever the mechanism may be, the fact remains that the plaque count on the basal medium plates yields a fair measure of the adsorbed fraction of the phage particles. We will cite as an example one experiment in which both of these methods were used on the same set of adsorption tubes (exp. 1).

\section{Experiment 1. Determination of adsorption by two methods}

1. By plaque count of free phage (supernatant on broth plates)

2. By plaque count of adsorbed phage (basal medium plates)

\begin{tabular}{c|c|c|c|c}
\hline & \multicolumn{3}{|c}{ COFACTORS ADDED TO ADSORPTION TUBE } \\
\cline { 2 - 4 } & $\begin{array}{c}\text { DL-Typtophan } \\
0.2 \mathrm{mg} / \mathrm{ml}\end{array}$ & $\begin{array}{c}\text { DL-Phenylalanine } \\
0.2 \mathrm{mg} / \mathrm{ml}\end{array}$ & N-Z-case 4 mg/ml & None \\
\hline & $\%$ & $\%$ & $\%$ & $\%$ \\
2 & 24 & 37 & 79 & -6 \\
& 21 & 32 & 73 & 0 \\
\hline
\end{tabular}

The second method gives slightly lower values for the adsorbed fraction than the first one. This means that not every adsorbed particle forms a plaque on basal medium plates. It is necessary, therefore, to check the second method with the first method for each new stock under investigation. This has been done for each stock described in this paper. In some cases it was found that the second method gives values less than 50 per cent of those obtained by the first method. In such cases also the appearance of the plaques on $\mathrm{F}$ agar is very poor and the count uncertain and variable. Nevertheless the second method is a valuable one, particularly in cases of slight adsorption where the first method yields only qualitative results. For the measurements cited here the second 
method gave at least 50 per cent of the adsorbed fraction. For each measurement cited we will indicate which of the two methods was used.

\section{Measurement of Cofactor Activity}

The function of the cofactors, according to T. F. Anderson (1948), is to "activate" the phage particles, i.e., to bring them into a state in which they can be adsorbed by the bacteria. The word "adsorption" is here used simply to designate the fact that phage particle and bacterium form a link that is not reversible by dilution or any other known treatment. It used to be thought that this linkage was analogous to the bonds formed between antigens and antibodies. Anderson's discovery of cofactor requirements points in a different direction. It may turn out that adsorption consists not merely in the formation of a static bond, controlled by secondary valencies, but involves enzymatic reactions. Whatever the mechanism, closer studies of the kinetics of cofactorcontrolled activation should help to get a clearer picture of its nature.

Cofactor activity can be demonstrated and titrated by two methods that measure the adsorption obtainable under different conditions.

(1) Activation prior to adsorption. The cofactor is added to a suspension of phage particles, and the mixture is incubated to permit the reaction between phage and cofactor to come to equilibrium. The mixture is then diluted with a large volume of bacterial suspension and plated after adsorption. Since deactivation of the phage particles after dilution is very rapid, only a fraction of the activated particles will be adsorbed after dilution. The adsorbed fraction will depend on the concentration of bacteria in a predictable way. T. F. Anderson (1948) has made ingenious use of this method to prove that deactivation proceeds exponentially, like the decay of a radio-active substance. The method may also be used to determine the dependence on the concentration of cofactor of the active fraction of phage at equilibrium. In agreement with Anderson we find that the active fraction drops very suddenly to zero when the concentration of cofactor is lowered below a certain threshold, characteristic for each cofactor (exp. 2).

Experiment 2. Activation of phage by various concentrations of cofactor (L-tryptophan)

Phage and cofactor equilibrated for 30 minutes at $37 \mathrm{C}$, diluted 1:25 with bacterial suspension, plated on basal medium 5 minutes later.

\begin{tabular}{l|l}
\hline L-rRYPTOPBAN & ADsORPTiON (MrTHOD 2) \\
\hline$\mu g / m l$ & $\%$ \\
2 & 5 \\
1 & 2.3 \\
0.5 & 0.8 \\
0.25 & 0.005 \\
0.125 & 0.005 \\
None & 0.004 \\
\hline
\end{tabular}

The active fraction drops by more than a factor of 100 when the concentration of cofactor is lowered from $0.5 \mu \mathrm{g}$ per $\mathrm{ml}$ to $0.25 \mu \mathrm{g}$ per $\mathrm{ml}$. 
(2) Activation during adsorption. The activity of a cofactor may also be demonstrated and titrated by adding the cofactor to the adsorption mixture, and by measuring the amount of adsorption obtained after a definite length of time. Under these conditions activation and deactivation of the phage particles and adsorption proceed simultaneously, and the amount of adsorption obtainable depends on the relative rates of these three processes. For this reason the measured adsorption is a more indirect measure of activation than that obtained by the first method. There are actually two further factors affecting the amount of adsorption obtainable by this method. First, the bacteria will metabolize the cofactor and change its concentration during the course of the experiment. Secondly, while metabolizing the cofactor, the bacteria may produce a substance that actively inhibits the activation of the phage particles by the cofactor. Each of these factors would have to be worked out quantitatively before activity measurements obtained by this method could be translated into terms of interaction between phage particles and cofactor. This has not yet been accomplished, and for this reason the activity measurements obtained by this method

TABLE 1

Relative activities of cofactors

\begin{tabular}{|c|c|}
\hline COFACTOR & CONCENTRATION POR HALF-MAXIMUK ADSORPTION \\
\hline & $\mu g / m b$ \\
\hline L-Tryptophan... & 1 \\
\hline DL-5-Methyl-tryptophan. . . . & 14 \\
\hline DL-Phenylalanine $\ldots \ldots \ldots \ldots \ldots \ldots \ldots$ & 18 \\
\hline L-Tyrosine $\ldots \ldots \ldots \ldots \ldots \ldots \ldots \ldots \ldots \ldots \ldots$ & 170 \\
\hline DL-Norleucine $\ldots \ldots \ldots \ldots \ldots \ldots \ldots \ldots$ & 340 \\
\hline
\end{tabular}

will not be given in detail. Notwithstanding these complications, this method is a convenient one for a rapid survey of a large number of potential cofactors and for a rough comparison of their relative activities. When the concentration of a given cofactor is varied, a result is obtained similar to that with the first method, namely, a threshold concentration of cofactor at which a rapid drop in activity occurs. In table 1 the concentrations of different cofactors are given at which half-maximum adsorption is obtained.

The weak activities of tyrosine and of norleucine might be suspected as due to impurities. However, they were rechecked and confirmed with highly purified samples of different origins.

\section{RESULTS}

The Stock T4,5

For most of the earlier experiments reported in this paper the stock T4,5 was used. This stock had been assumed to be reasonably pure since (1) it was isolated from a single plaque and (2) since it exhibited no heterogeneity in plaque morphology when plated on broth plates.

However, during the course of these experiments it became quite apparent 
that $T 4,5$ is inhomogeneous with respect to the very character under investigation, viz., its cofactor requirement. Only 25 per cent of the particles of this stock were adsorbable on bacteria in a synthetic medium in the presence of any amount of tryptophan. It could be shown that this result was not due to any sort of kinetic equilibrium between adsorption and desorption, or activation and deactivation, but to a true inhomogeneity among the particles of the stock, and this inhomogeneity could be used to separate the stock into fractions of different adsorbability (exp. 3).

Experiment 3. Fractionation of stock $T 4,5$

\begin{tabular}{|c|c|}
\hline & ADSORPTION (KETHOD 2) \\
\hline & $\%$ \\
\hline $\begin{array}{r}\text { Adsorb } \mathrm{T} 4,5 \text { on } \mathrm{B} \text { in presence of } 4 \mu \mathrm{g} / \mathrm{ml} \\
\text { L-tryptophan. } \ldots \ldots \ldots \ldots \ldots \ldots \ldots\end{array}$ & 20 \\
\hline 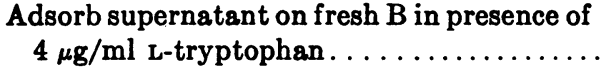 & 3.7 \\
\hline
\end{tabular}

It is quite apparent from these experiments that the fraction that does not respond to the cofactor tryptophan must be adsorbable in the presence of some other, or some additional, cofactor, since this fraction is adsorbable in the presence of broth. Further experiments, involving tests on the contents of individual plaques, showed that the character difference here encountered might be a hereditary character of sufficient stability to make worth while an attempt at obtaining pure stocks. Consequently, suitable single plaque isolations were made, as indicated below, which led to stocks with the desired properties.

\section{Preparation of Stocks with Different Cofactor Requirements}

(1) A stock of particles adsorbable with tryptophan as the only supplement to F medium.

T4,5 was adsorbed on B in the presence of $4 \mu \mathrm{g}$ per $\mathrm{ml} \mathrm{L}$-tryptophan, and plated on $\mathrm{F}$ plates. Under these conditions the nonadsorbable fraction will be prevented from forming plaques. A single plaque was picked into a suspension of bacteria in broth, incubated, and filtered after lysis. This is stock T4,11.

(2) A stock of particles not adsorbable with tryptophan as the only supplement to $\mathrm{F}$ medium.

T4,5 was adsorbed on B in the presence of $4 \mu \mathrm{g}$ per ml L-tryptophan, as above. After adsorption the mixture was centrifuged and the supernatant plated on broth plates. Adsorption and centrifugation removed the adsorbable fraction, and every plaque represents the progeny of a particle nonadsorbable with tryptophan alone. One such plaque was picked into a suspension of bacteria in broth, incubated, and filtered after lysis. This is stock T4,12.

The two stocks differ strikingly in their response to tryptophan. T4,11 is as highly adsorbable with tryptophan as with broth, whereas T4,12 gives very low adsorption with tryptophan but high adsorption with broth. The question 
regarding the nature of the cofactor requirements of $\mathrm{T} 4,12$ arises, and this will be taken up next.

\section{Identification of the Cofactor Requirements of T4,12}

At first it was assumed that $\mathrm{T} 4,12$ requires as cofactor an organic compound different from tryptophan. A systematic search was undertaken using the customary techniques for identification of the growth factor requirements of microorganisms. An aliquot of the material to be assayed for cofactor activity was added to a mixture of bacteria and $\mathrm{T} 4,12$, and this mixture was plated after 10 minutes in parallel on $\mathrm{F}$ plates and on broth plates. High activity was shown by broth, N-Z-case, yeast extract, and acid-hydrolyzed yeast extract; very low activity was shown by acid-hydrolyzed casein with or without a supplement of tryptophan. Of the individual amino acids only tryptophan and phenylalanine at $25 \mu \mathrm{g}$ per $\mathrm{ml}$ showed a slight activity. A mixture of the known vitamins plus acid-hydrolyzed nucleic acid was inactive.

TABLE 2

Properties of stocks T4,11 and T4,12

\begin{tabular}{|c|c|c|}
\hline \multirow{4}{*}{ COYACTORS IN ADSORPTION TUBE } & \multicolumn{2}{|c|}{ TITER } \\
\hline & $\mathbf{T} 4,11$ & $\mathrm{~T} 4,12$ \\
\hline & $3 \times 1010$ & $5.7 \times 10^{10}$ \\
\hline & \multicolumn{2}{|c|}{ Adsorption (method 2) } \\
\hline 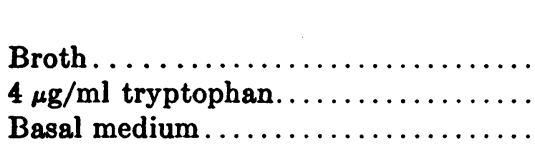 & \begin{tabular}{l}
\multicolumn{1}{c}{${ }^{\circ}$} \\
$90^{2}$ \\
0.001
\end{tabular} & \begin{tabular}{l}
\multicolumn{1}{c}{$\%$} \\
80 \\
4.3 \\
0.001
\end{tabular} \\
\hline
\end{tabular}

Since these findings, as well as several others, did not give a clear lead to an organic compound, we suspected that an inorganic ion might be involved. Of these, the ions of $\mathrm{Na}, \mathrm{K}, \mathrm{Mg}, \mathrm{Cl}$, and phosphate could be excluded since they are present in our basal medium. Since calcium ions have been shown to affect several phage-bacterial systems, we suspected that here too calcium ion might be involved. This turned out to be correct, as may be seen from the results of experiment 4 .

Experiment 4. Adsorption of T4,12 with varying amounts of L-tryptophan and $\mathrm{CaCl}_{2}$

\begin{tabular}{|c|c|c|c|c|}
\hline \multirow{3}{*}{$\mu g / m l$ L-TRYPTOPEAN } & \multicolumn{4}{|c|}{ PLAQUE COUNTS ON BASAL MEDIUK PLATES } \\
\hline & \multicolumn{4}{|c|}{$\mu \mathrm{g} / \mathrm{ml} \mathrm{CaCl}$} \\
\hline & 0 & 8 & 32 & 128 \\
\hline $\begin{array}{r}0 \\
25 \\
100\end{array}$ & $\begin{array}{r}0 \\
74 \\
71\end{array}$ & $\begin{array}{r}0 \\
373 \\
419\end{array}$ & $\begin{array}{r}0 \\
551 \\
565\end{array}$ & $\begin{array}{r}0 \\
513 \\
565\end{array}$ \\
\hline
\end{tabular}


This experiment shows that in the presence of tryptophan, $\mathrm{CaCl}_{2}$ very much increases the number of phage-bacterium complexes capable of plaque formation on $\mathrm{F}$ agar plates. Other tests showed that close to 100 per cent of the phage particles form plaques if the medium contains more then $10 \mu \mathrm{g}$ per $\mathrm{ml}$ of tryptophan and of $\mathrm{CaCl}_{2}$ each. About 30 per cent of the phage particles form plaques in the presence of $2 \mu \mathrm{g}$ per $\mathrm{ml}$ of each of the cofactors.

Experiment 5 was designed to decide whether $\mathrm{CaCl}_{2}$ is merely an activator of a phage-bacterium complex formed independently of it or whether it is necessary for the adsorption process. The experiment shows that $\mathrm{Ca}^{++}$is necessary for adsorption.

Experiment 5. Adsorption of $\mathrm{T}_{4}, 12$ with and without $\mathrm{CaCl}_{2}$

Adsorption mixtures with and without calcium ions were set up in parallel, and free phage was measured after 10 minutes in the usual manner. Both adsorption mixtures contained $4 \mu \mathrm{g}$ per $\mathrm{ml} \mathrm{L}$-tryptophan, and one of them contained $4 \mu \mathrm{g}$ per $\mathrm{ml} \mathrm{CaCl}_{2}$.

\begin{tabular}{|c|c|}
\hline IN ADSORPTION TUBE & ADSORPTION (METHOD 1) \\
\hline $\begin{array}{l}4 \mu \mathrm{g} / \mathrm{ml} \text { L-tryptophan } \ldots \ldots \ldots \ldots \ldots \ldots \ldots \\
4 \mu \mathrm{g} / \mathrm{ml} \text { L-tryptophan plus } 4 \mu \mathrm{g} / \mathrm{ml} \mathrm{CaCl}_{2} \ldots\end{array}$ & $\begin{array}{c}\% \\
13 \\
68\end{array}$ \\
\hline
\end{tabular}

The requirement of $\mathrm{T} 4,12$ for $\mathrm{Ca}^{++}$is a specific one, in the sense that $\mathrm{Ca}^{++}$ cannot be replaced by $\mathrm{Mg}^{++}$ion, since the minimal medium used in all the tests ( $F$ medium) contains $20 \mu \mathrm{g} \mathrm{Mg}{ }^{++}$per $\mathrm{ml}$. Also the $\mathrm{Ca}^{++}$requirement of $\mathrm{T} 4,12$ does not constitute a specialization of a general requirement for divalent cations, possibly present in all mutants. T4,11 was tested for adsorbability in the presence of L-tryptophan using a modified basal medium in which $\mathrm{MgSO}_{4}$ was replaced by $\mathrm{K}_{2} \mathrm{SO}_{4}$. This medium contains no divalent cations, but their absence did not affect the adsorbability of T4,11.

It is true that for many phages the adsorption process is dependent on the presence of electrolytes, and T4 with all the mutants here studied belongs in this group. In salt-free media no adsorption takes place. The salt requirement, however, is nonspecific with respect to the chemical nature of the ions and lies in a concentration range about a thousand times higher than the specific $\mathrm{Ca}^{++}$ requirement of $T 4,12$. The unspecific salt requirement presumably influences the electrostatic properties of the bacteria and of the phage particles.

\section{Inhibition of Adsorption by Metabolic Products of Tryptophan}

Tryptophan is a substrate actively metabolized by $E$. coli. Therefore, if tryptophan is incubated with bacteria, it will disappear in due course. It was thought that the cofactor activity of tryptophan might be used to follow quantitatively the progress of the disappearance of tryptophan. It turned out, however, that the bacteria produce from tryptophan a substance or substances that actively inhibit the adsorption of the cofactor-requiring phages (exp. 6). 
Experiment 6. Inhibition of adsorption of $T 4,18$ by preincubation of bacteria for 2 hours with $4 \mu \mathrm{g}$ per ml L-tryptophan

A growing culture of $B$ in $F$ medium was divided into two equal portions, to one of which $4 \mu \mathrm{g}$ per ml L-tryptophan were added, and both cultures were incubated for 2 hours. To both cultures were then added $4 \mu \mathrm{g}$ per $\mathrm{ml}$ L-tryptophan, $4 \mu \mathrm{g}$ per $\mathrm{ml} \mathrm{CaCl}_{2}$, and $\mathrm{T} 4,12$, and the adsorption of $\mathrm{T} 4,12$ on the bacteria was determined.

\begin{tabular}{|c|c|c|}
\hline & \multicolumn{2}{|c|}{ ADSORPTION } \\
\hline & METHOD 1 & METHOD 2 \\
\hline 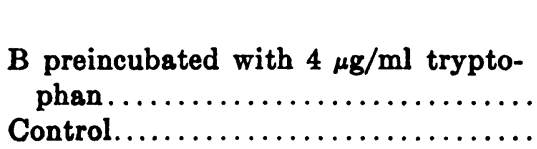 & $\begin{array}{l}\% \\
20 \\
80\end{array}$ & $\begin{array}{r}\% \\
4 \\
75\end{array}$ \\
\hline
\end{tabular}

It is clear from this experiment that bacteria preincubated with tryptophan will not adsorb $\mathrm{T} 4,12$ in the presence of more tryptophan and $\mathrm{Ca}^{++}$. In experiment 7 various periods of preincubation with tryptophan were compared.

Experiment 7. Dependence of inhibition on time of preincubation with tryptophan

\begin{tabular}{|c|c|}
\hline TREE OF PREINCOBATION YENOTHS & ADSORPTION (LCTTHOD 2) \\
\hline & $\%$ \\
\hline 0 & 86 \\
\hline $\mathbf{5}$ & 58 \\
\hline 15 & 9 \\
\hline 30 & 4.4 \\
\hline 60 & 4.0 \\
\hline 180 & 4.7 \\
\hline
\end{tabular}

The inhibition created by preincubation with $4 \mu \mathrm{g}$ per ml L-tryptophan is not overcome by adding to the adsorption tube 10 times this amount of L-tryptophan, nor by adding $40 \mu \mathrm{g}$ per ml DL-phenylalanine (exp. 8).

Experiment 8. Inability of phenylalanine and of large amounts of tryptophan to overcome the inhibition created by preincubation with $4 \mu \mathrm{g}$ per $\mathrm{ml}$ L-tryptophan

\begin{tabular}{|c|c|}
\hline COTACTOR & ADSORPTION (KXTTHOD 2) \\
\hline 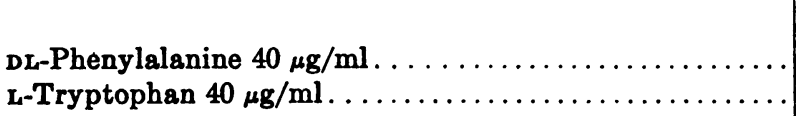 & $\begin{array}{l}\% \\
0.2 \\
2\end{array}$ \\
\hline
\end{tabular}

The dependence of the inhibition on the amount of tryptophan added at the beginning of the preincubation period was measured next. The duration of preincubation was kept constant at 60 minutes, and the amount of tryptophan added with the phage was also kept constant at $4 \mu \mathrm{g}$ per ml (exp. 9). 
Experiment 9. Dependence of inhibition on amount of tryptophan in preincubation tube (Preincubation for 60 minutes. Four $\mu \mathrm{g}$ per $\mathrm{ml} \mathrm{L}$-tryptophan added to adsorption tube.)

\begin{tabular}{c|c}
\hline L-TRYPTOPHAN IN PREINCUBATION TUBE & ADSORPTION (METHOD 2) \\
\hline$\mu g / m l$ & $\%$ \\
0 & 53 \\
0.5 & 35 \\
1 & 22 \\
2 & 13 \\
4 & 3 \\
40 & 1 \\
\hline
\end{tabular}

In a parallel experiment $80 \mu \mathrm{g}$ per $\mathrm{ml}$ DL-phenylalanine were added to the preincubation mixture, instead of tryptophan (exp. 10). This treatment did not inhibit adsorption.

Experiment 10. Does preincubation with phenylalanine cause inhibition of adsorption in presence of $4 \mu g$ per $m l$ L-tryptophan?

\begin{tabular}{|c|c|}
\hline B PREINCUBATED WITH & ADSORPTION (METHOD 2) \\
\hline & $\%$ \\
\hline DL-Phenylalanine $80 \boldsymbol{\mu g} / \mathrm{ml} \ldots \ldots \ldots \ldots \ldots \ldots \ldots \ldots \ldots \ldots \ldots$ & 70 \\
\hline 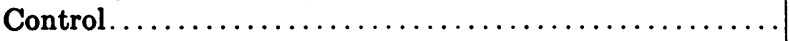 & 53 \\
\hline
\end{tabular}

From the preceding experiments we conclude that the inhibition is created by preincubation with tryptophan, but not by preincubation with phenylalanine. Further, we conclude that the inhibition is established in about 15 minutes, that a few $\mu \mathrm{g}$ of tryptophan are sufficient to establish the inhibition, that the inhibition cannot be overcome by 10 times the amount of tryptophan added to the adsorption tube, and that inhibition established by preincubation with tryptophan is also not overcome by adding phenylalanine in large amounts to the adsorption tube.

Experiment 11 was designed to test whether the inhibition is due to a change in the bacteria or to a change in the medium. A culture of bacteria was inhibited by preincubation with $4 \mu \mathrm{g}$ per $\mathrm{ml} \mathrm{L}$-tryptophan for 60 minutes. It was then mixed with an equal volume of a similar culture incubated without tryptophan. This culture was therefore not inhibited.

Experiment 11. Does preincubation with tryptophan produce a diffusible substance inhibiting the adsorption of T4,12 on freshly added bacteria?

\begin{tabular}{|c|c|}
\hline & ADSORPTION (KETHOD 2) \\
\hline & $\%$ \\
\hline Noninhibited culture............. & 53 \\
\hline Inhibited culture $\ldots \ldots \ldots \ldots \ldots \ldots \ldots \ldots \ldots \ldots \ldots \ldots$ & 3 \\
\hline 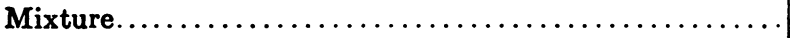 & 10 \\
\hline
\end{tabular}


Experiment 11 shows that the medium of the inhibited culture contains a substance or substances, produced by the bacteria in the presence of tryptophan, which prevent the adsorption of phage on bacteria. These substances must be free in solution since adsorption to freshly added bacteria is inhibited as strongly as adsorption to bacteria that caused this metabolic transformation of tryptophan. In the next experiment a similar result was obtained by testing the supernatant of an inhibited culture for its inhibitory power by adding it in equal volume to a noninhibited culture (exp. 12).

Experiment 12. Test of supernatant of inhibited culture

\begin{tabular}{|c|c|}
\hline NONLAIBITED CULTURE MAXED WITH FQUAL VOLUME OF & ADSORPTION (METHOD 2) \\
\hline $\begin{array}{l}\text { Supernatant of inhibited culture } \ldots \ldots \ldots \ldots \ldots \ldots \ldots \ldots \ldots \ldots \ldots \ldots \ldots \ldots \ldots \ldots \ldots \ldots \ldots \ldots \\
\text { Basal medium } \ldots \ldots \ldots \ldots \ldots \ldots \ldots \ldots \ldots\end{array}$ & $\begin{array}{r}\% \\
2 \\
25\end{array}$ \\
\hline
\end{tabular}

In experiment 13 known products of tryptophan metabolism were tested individually for inhibitory power. These suspected inhibitory factors were added to a bacterial suspension immediately before adding a mixture of phage, L-tryptophan, and $\mathrm{CaCl}_{2}$. In the adsorption mixtures the concentrations of inhibitory factor, tryptophan, and $\mathrm{CaCl}_{2}$ were $5 \mu \mathrm{g}$ per $\mathrm{ml}$ of each. Ten minutes were allowed for adsorption, and then the mixtures were plated on broth (for the count of total phage) and on plates of $\mathrm{F}$ medium (for the count of adsorbed phage), and the supernatant was plated on broth (for the count of free phage).

Experiment 13. Tests for inhibition of adsorption by known products of tryptophan metabolism

\begin{tabular}{|c|c|c|}
\hline \multirow{2}{*}{ IN ADSORPTION TUBE $5 \mu \mathrm{g} / \mathrm{ml}$ L-TRYPTOPHAN AND $5 \mu \mathrm{g} / \mathrm{ml}$ OF } & \multicolumn{2}{|c|}{ ADSORPTION } \\
\hline & METHOD 1 & METHOD 2 \\
\hline & $\%$ & $\%$ \\
\hline 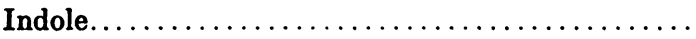 & 3.3 & 17 \\
\hline 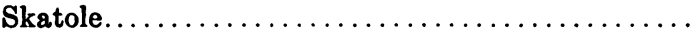 & 19 & 一 \\
\hline Indole-3-acetic acid $\ldots \ldots \ldots \ldots \ldots \ldots \ldots \ldots$ & 72 & 86 \\
\hline Indole-3-propionic acid $\ldots \ldots \ldots \ldots \ldots \ldots \ldots$ & 74 & 74 \\
\hline Tryptamine $\ldots \ldots \ldots \ldots \ldots \ldots \ldots \ldots$ & 65 & 72 \\
\hline $100 \mu \mathrm{g} / \mathrm{ml}$ DL-serine. . . . . . . . . . . . . . . & 70 & 62 \\
\hline 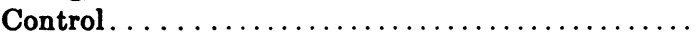 & 71 & 78 \\
\hline
\end{tabular}

Of the substances here tested, only indole and skatole showed definite inhibitory power, with indole the more active of the two. All subsequent tests were confined to indole. The inhibition is clearly an inhibition of adsorption. The inhibitory activity of indole on the adsorption of T4,12 in the presence of $5 \mu \mathrm{g}$ per $\mathrm{ml} \mathrm{L}$-tryptophan and $\mathrm{CaCl}_{2}$ is brought out more strikingly in the following titration series (exp. 14). 
Experiment 14. Titration of indole against $5 \mu \mathrm{g} / \mathrm{ml}$ L-tryptophan

\begin{tabular}{l|c}
\hline INDOLE & ADSORPTION (CETHOD 2) \\
\hline Mg/mb & $\%$ \\
4 & 0.5 \\
2 & 1.7 \\
1 & 4.4 \\
0.5 & 13 \\
0.2 & 32 \\
0.1 & 39 \\
0 & 58 \\
\hline
\end{tabular}

Indole can exert a noticeable inhibitory action even at a concentration of $0.1 \mu \mathrm{g}$ per $\mathrm{ml}, 50$ times lower than that of L-tryptophan.

The preceding experiments have shown that the bacteria produce from $L$ tryptophan (but not from phenylalanine) a substance or substances capable of inhibiting the adsorption of $\mathrm{T} 4,12$ in the presence of $\mathrm{L}$-tryptophan and $\mathrm{CaCl}_{2}$. Among known or suspected products of tryptophan metabolism indole, and to a lesser extent skatole, were found to have such inhibitory activity. Anderson has shown that the function of the cofactor, L-tryptophan, is to activate the phage particles reversibly. It seems natural to assume that the inhibitory substances function by forming competitive combinations with the phage particles.

Several pieces of evidence can be brought forward that may serve to elaborate and in some measure to support this idea. In an experiment already reported (exp. 8.) it was shown that the products of tryptophan metabolism are inhibitory also against phenylalanine. This may indicate that phenylalanine exerts its cofactor activity as a true tryptophan analogue, combining with the phage in the same places where tryptophan combines. Experiment 15 shows that indole is active against every cofactor contained in broth.

Experiment 15. Inhibitory action of indole against all cofactors contained in broth

\begin{tabular}{|c|c|c|}
\hline \multirow{2}{*}{ IN ADSORPTION TUBE $4 \mathrm{mg} / \mathrm{ml}$ BROTH AND } & \multicolumn{2}{|c|}{ ADSORPTION } \\
\hline & METHOD 1 & LETHOD 2 \\
\hline $\begin{array}{l}50 \mu \mathrm{g} / \mathrm{ml} \text { indole } \ldots \ldots \ldots \ldots \ldots \ldots \ldots \ldots \ldots \ldots \ldots \ldots \\
\text { Control (no indole) } \ldots \ldots \ldots \ldots \ldots \ldots \ldots \ldots \ldots \ldots\end{array}$ & $\begin{array}{c}\% \\
18 \\
88\end{array}$ & $\begin{array}{c}\% \\
4.2 \\
91\end{array}$ \\
\hline
\end{tabular}

The idea that indole acts by establishing a competitive block at the points where tryptophan (or its analogues) reacts with the phage implies that it should inhibit the adsorption of all those, and only those, phage mutants that require tryptophan (or one of its analogues) as cofactors. Specifically, indole should inhibit the adsorption of $\mathrm{T} 4,11$, which requires tryptophan but not $\mathrm{Ca}^{++}$, and should not inhibit $\mathrm{T} 4,1$, which does not require any cofactor. These inferences are verified by the results of experiments 16 and 17 . 
Experiment 16. Inhibition of adsorption of T4,11 by varying amounts of indole

\begin{tabular}{c|c}
\hline IN ADSORPTION TUBE $5 \mu \mathrm{g} / \mathrm{ml}$ L-TRYPTOPHAN AND INDOLE & ADSORPTION (METHOD 2) \\
\hline$\mu g / m l$ & $\%$ \\
40 & 8.5 \\
20 & 12 \\
10 & 18 \\
4 & 23.5 \\
2 & 31 \\
1 & 54 \\
0 & 75 \\
\hline
\end{tabular}

Experiment 17. Noninhibition of adsorption of T4,1 by indole

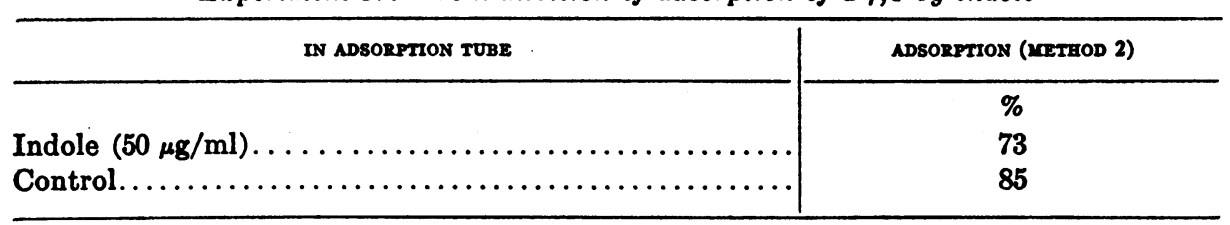

Note: Stock T4,1 is not a pure stock. It contains about 10 per cent phage particles giving plaques with fuzzy margins, like the wild type. These 10 per cent are cofactorrequiring. In the experiment just cited these particles were not adsorbed in either the indole or the control tube. These particles, which give clearly distinguishable plaques, were not counted for the evaluation of adsorption.

Experiments 16 and 17 show that indole inhibition is specific for those mutants requiring tryptophan as cofactor for adsorption. It should be noted, however, that $\mathrm{T} 4,11$ is about 10 times less sensitive than $\mathrm{T} 4,12$ to the inhibitory action of indole.

\section{DIscussion}

The experiments here reported show that mutations of phages with respect to cofactor requirements do occur and that mutant stocks of reasonable purity can be prepared. Very little is known about the rates at which the mutations occur and about the conditions that influence the rates of mutation. In some cases the rates must be quite high, so high, in fact, that it becomes a matter of chance whether a reasonably pure stock is obtained.

The biochemical deficiencies of the mutants are concerned with the requirements of the phages for the adsorption process. It must be clearly understood that the term "adsorption," as it is used in virus research, refers to the occurrence of an irreversible, specific union between virus particles and host. A physical adsorption, meaning a static bond, like that between antigen and antibody, may or may not be a step in the biological adsorption process. It seems reasonable to postulate an intermediate step between the hypothetical physical adsorption and the beginning of multiplication of the parasite. For want of a better term we will call this intermediate step the "invasion," meaning a chemical reaction, presumably enzymatically controlled, by which the physically adsorbed particle effects an entry into the host cell. One may imagine that the physical adsorption 
process in some cases is reversible and that the observed irreversible adsorption is a combination of physical adsorption followed by invasion. It seems reasonable that biochemical deficiencies of phages (and perhaps of all viruses) should be concerned primarily with the invasion phase of the life cycle of the particles. Once a virus particle has entered a host cell, it is not so likely to be dependent on supplementary factors in the medium, beyond those required by the host itself, since the host cell should provide everything that is necessary.

Anderson's discovery. of cofactor requirements of phages, implying that resistance or sensitivity of a host to a virus may be conditioned by the presence or absence of specific factors in the medium, surely constitutes an extraordinary advance in the general approach to problems of virus virulence. Our findings extend this discovery in several directions.

First, they show that mutations occur that make a virus independent of a cofactor. Such a mutation may be looked upon as a host range mutation. Thus, T4,1 will attack strain $\mathrm{B}$ in $\mathrm{F}$ medium, whereas $\mathrm{T} 4,11$ and $\mathrm{T} 4,12$ will not. T4,1, therefore, could be looked upon as a host range mutant with respect to the basal medium used.

Secondly they show that viruses with cofactor requirements can be interfered with, apparently by interfering with the utilization of the cofactor by the virus. Thus the attack of $T 4,11$ or of $T 4,12$ on $B$ in the presence of any of the cofactors can be blocked by the presence of indole. In this system indole plays the role of an antivirus drug, and to our knowledge it is the first drug on record that specifically protects a host cell from a virus invasion. This action must not be confused with that of other drugs (2- and 3-pyridyl-alanine, for instanceT. F. Anderson, 1946), which block the liberation of active phage particles from infected bacteria, but which do not prevent the adsorption of the phage particles. These drugs, too, effectively block the spread of phage infection in a bacterial culture by confining the infection to the cells first attacked.

Third, since the bacteria here studied produce indole from tryptophan, our findings point to a peculiar mechanism of self-protection on the part of the bacteria, converting an activator of an invasive pathogen into an inhibitor. We are inclined to see in this interrelationship a first rational link between the metabolic pattern of the host and its resistance pattern. That there do exist links between the metabolic and the resistance pattern is certainly to be expected, and indeed such links have been shown to exist in several instances (E. H. Anderson, 1944, 1946; Wollman, 1947). Some of the bacterial mutations from phage sensitivity to phage resistance have been found to be associated with loss of ability to synthesize either tryptophan or proline. There is in these cases no obvious rational connection between the change of the metabolic pattern and the change of the resistance pattern of the bacteria, since the phages involved are not known to have cofactor requirements. The two changes appear to be accidentally linked phenotypic expressions of certain mutational steps. It might be worth while, however, to look more closely into the details of the metabolism of tryptophan and related substances in connection with the resistance pattern.

Finally, the finding that bacteria metabolically produce certain phage inhibi- 
tors may help to elucidate a variety of odd findings concerning the development in phage lysate of secondary bacterial growths, which on isolation turn out to be growths of sensitive bacteria. Probably every worker is familiar with this phenomenon, and occasionally one also finds it mentioned in the literature. A particularly striking case has been described recently by Kleczkowska (1945). In none of these cases, apparently, have the "antilysin" or "inhibitor" been identified chemically; and, indeed before Anderson's discovery of the simple chemical nature of a cofactor, it would have seemed a wild surmise to expect the antilysin to be a simple chemical substance. From here on out, the hunt for other simple antilysins is likely to be a lively one.

\section{SUMMARY}

Mutant stocks of phage T4 are described that differ from one another with respect to their requirements for cofactors of adsorption. Table 3 summarizes the properties of the principal stocks.

TABLE 3

Properties of mutant stocks of T4

\begin{tabular}{|c|c|c|c|}
\hline YUTANT STOCK & $\begin{array}{l}\text { PLAQUES ON BROTH } \\
\text { PLATES }\end{array}$ & COFACTOR REQUIREMENT & INHIBITION BY INDOLE \\
\hline $\begin{array}{l}\mathrm{T} 4,1 \\
\mathrm{~T} 4,11 \\
\mathrm{~T} 4,12\end{array}$ & $\begin{array}{l}\text { Sharp } \\
\text { Fuzzy } \\
\text { Fuzzy }\end{array}$ & $\begin{array}{l}\text { None } \\
1 \mu \mathrm{g} / \mathrm{ml} \text { L-tryptophan or } \\
\text { analogues } \\
\text { Same plus } 1 \mu \mathrm{g} / \mathrm{ml} \mathrm{Ca}+\end{array}$ & $\begin{array}{l}\text { No } \\
\text { Yes } \\
1 \mu \mathrm{g} / \mathrm{ml} \\
\text { Yes } \\
0.1 \mu \mathrm{g} / \mathrm{ml}\end{array}$ \\
\hline
\end{tabular}

Indole, which is metabolically produced from tryptophan by the bacteria, inhibits the activation of phage by tryptophan.

Possible relations between the metabolic and the resistance pattern of bacteria are discussed.

\section{REFERENCES}

ANDERson, E. H. 1944 Incidence of metabolic changes among virus-resistant mutants of a bacterial strain. Proc. Natl. Acad. Sci. U. S., 30, 397-403.

ANDERson, E. H. 1946 Growth requirements of virus-resistant mutants of Escherichia coli strain "B." Proc. Natl. Acad. Sci. U. S., 32, 120-128.

Anderson, T. F. 1945a The role of tryptophane in the adsorption of two bacterial viruses on their host, E. coli. J. Cellular Comp. Physiol., 25, 17-26.

Anderson, T. F. $1945 b$ The activity of a bacteriostatic substance in the reaction between bacterial virus and host. Science, 101, 565-566.

Anderson, T. F. 1946 Morphological and chemical relations in viruses and bacteriophages. Cold Spring Harbor Symposia Quant. Biol., 11, 1-13.

Anderson, T. F. 1948 The activation of the bacterial virus T4 by L-tryptophan. J. Bact., 65, 637-649.

Delbrück, M., AND BaIlex, W. T., JR. 1946 Induced mutation in bacterial viruses. Cold Spring Harbor Symposia Quant. Biol., 11, 33-37. 
Hersere , A. D. 1946a Mutation of bacteriophage with respect to type of plaque. Genetics, 31, 620-640.

HersheY, A. D. $1946 b$ Spontaneous mutations in bacterial viruses. Cold Spring Harbor Symposia Quant. Biol., 11, 67-76.

KLaczkowskA, J. 1945 A quantitative study of the interaction of bacteriophage with Rhizobium using the technique of poured plates. J. Bact., 50, 81-94.

Lunis, S. E. 1945 Mutations of bacterial viruses affecting their host range. Genetics, 30, 84-99.

LURIA, S. E. 1947 Reactivation of irradiated bacteriophage by transfer of self-reproducing units. Proc. Natl. Acad. Sci. U. S., 33, 253-264.

Wollman, E. 1947 Relation entre le pouvoir de synthétiser la proline et la résistance au bactériophage chez des mutants d'Escherichia coli. Ann. inst. Pasteur, 73, 348-364. 